\title{
Response of Serotonergic Caudal Raphe Neurons in Relation to Specific Motor Activities in Freely Moving Cats
}

\author{
Sigrid C. Veasey, ${ }^{1}$ Casimir A. Fornal, ${ }^{2}$ Christine W. Metzler, ${ }^{2}$ and Barry L. Jacobs ${ }^{2}$ \\ ${ }^{1}$ Pulmonary and Critical Care Division, Department of Medicine, and Center for Sleep and Respiratory \\ Neurobiology, University of Pennsylvania, Philadelphia, Pennsylvania and ${ }^{2}$ Program in Neuroscience, Princeton \\ University, Princeton, New Jersey
}

Serotonergic neuronal responses during three specific motor activities were studied in nuclei raphe obscurus (NRO) and raphe pallidus (NRP) of freely moving cats by means of extracellular single-unit recordings. Responses to treadmill-induced locomotion were primarily excitatory, with 21 of 24 neurons displaying increased firing rates, directly related to treadmill speed. Individual regression analyses determined three response patterns: maximal activation at low speed $(0.25 \mathrm{~m} / \mathrm{sec})$, augmentation of neuronal activity only at high treadmill speed $(0.77 \mathrm{~m} / \mathrm{sec})$, and a linear increase. A smaller fraction of NRO and NRP serotonergic neurons (6 of 27) also responded to hypercarbic ventilatory challenge with increased firing rates. The magnitude of neuronal response was dependent upon the fraction of inspired $\mathrm{CO}_{2}$ and was related to ventilatory motor output, specifically, inspiratory amplitude. A subgroup of neurons responsive to hypercarbia in wakefulness demonstrated significant reductions in neuronal response to hypercarbia in slow-wave sleep. Finally, unit activity for 12 of 29 cells increased in response to spontaneous feeding, displaying two distinct patterns of neuronal response in relation to onset and termination of feeding: rapid activation and deactivation versus a gradual increase and decrease. More than half of the cells studied under all three conditions were responsive to more than one motor task. These results indicate that serotonergic caudal raphe neurons are responsive to specific motor system challenges, with many neurons responsive to multiple motor tasks, and that the responsiveness of serotonergic neurons to at least one motor task, hypercarbic ventilatory challenge, is state dependent.

[Key words: single-unit activity, nucleus raphe obscurus, nucleus raphe pallidus, serotonin (5-HT), locomotion, treadmill, $\mathrm{CO}_{2}$, ventilation, motor, feeding, 8-OH DPAT, sleep]

Neurons within nuclei raphe obscurus (NRO) and raphe pallidus (NRP) project densely to brainstem and spinal motoneurons in all vertebrates studied (Kuypers, 1981; Willis, 1984; Jacobs and

\footnotetext{
Received Jan. 26, 1995; revised Mar. 9, 1995; accepted Mar. 14, 1995.

This work was supported in part by grants from NIMH (23433), NIH (HL42236, HL-02838), and DOD (AFOSR-0294).

Correspondence should be addressed to Sigrid Carlen Veasey, M.D., Center for Sleep and Respiratory Neurobiology, Hospital of the University of Pennsylvania, 985-A Maloney Building, 3600 Spruce Street, Philadelphia, PA $19104-4283$.

Copyright $\subset 1995$ Society for Neuroscience $0270-6474 / 95 / 155346-14 \$ 05.00 / 0$
}

Azmitia, 1992), implying a significant role for caudal raphe neurons in the control of motor function. The majority (over $85 \%$ ) of NRO and NRP neurons projecting to the spinal cord in cats are serotonergic neurons (Bowker et al., 1987). Microinjection of serotonin (5-HT) into brainstem motor nuclei in vivo results in a tonic increase in the electromyographic (EMG) activity of innervated muscles (Ribiero-do-Valle et al., 1991) and a tonic increase in motoneuronal activity (Kubin et al., 1992). Additionally, both electrical and chemical stimulation of NRO and NRP result in a similar tonic excitation of lumbar (Roberts et al., 1988; Fung and Barnes, 1989) and phrenic motoneurons (Holtman et al., 1986a; Millhorn, 1986). Holtman et al. (1986b) demonstrated a significant role for 5-HT in the enhancement of phrenic motoneuronal activity induced by raphe stimulation by showing that systemic administration of 5-HT antagonists markedly depresses the phrenic response. Results from these studies support the hypothesis that the raphe-motor system functions as a gain-setter of motor activity (McCall and Aghajanian, 1979) and that 5-HT functions as one of the critical facilitatory neurotransmitters for this system.

What remains unclear, however, is when this system is called into play. One technique that allows determination of the involvement of medullary raphe neurons in motor tasks is the study of neuronal activity by means of extracellular recording in freely moving animals (Heym and Jacobs, 1986). In the present study, we employed this technique to evaluate the responsiveness of caudal raphe serotonergic neurons to motor system challenges in cats. We hypothesized that subsets of these neurons would respond to specific motor tasks. Two motor systems selected for study were those mediating locomotion and ventilation. Levels of physiological challenge for both systems can be readily quantified (van Lunteren, 1987; Gregor et al., 1988). For comparison with these motor responses, which are mediated primarily by spinal cord motoneurons, we also studied neuronal activity during spontaneous feeding (chewing, licking, and swallowing), which is mediated primarily by brain stem motoneurons.

An intriguing characteristic of all serotonergic raphe neurons is their strong sleep state dependence in firing rate (McGinty and Harper, 1976; Heym et al., 1982; Jacobs and Fornal, 1991). Indeed, the firing rates of serotonergic medullary raphe neurons are reduced in slow-wave sleep (SWS) and fall nearly silent in rapid-eye-movement sleep (REMS) (Heym et al., 1982). One motor system that must maintain activity in sleep is the ventilatory system. Responses, however, to ventilatory challenges are blunted in sleep (Phillipson et al., 1976). We therefore hypoth- 
esized that this reduced ventilatory responsiveness in sleep may be a consequence of reduced activity of these facilitatory premotoneurons during sleep. Therefore, a second purpose of this study was to compare the waking and sleep responses of caudal raphe serotonergic neurons to hypercarbic ventilatory challenge.

\section{Materials and Methods}

Twelve adult male cats weighing $2.3-5.7 \mathrm{~kg}$ were studied. The cats were housed individually within a USDA-approved colony and maintained on a 14:10 light-dark cycle, with the lights on at 0800 . Food and water were available ad libitum. $\Lambda$ ll procedures were reviewed and approved by the Institutional Animal Care and Use Committee for Princeton University.

\section{Surgical procedures}

Preoperatively, cats received $200 \mu \mathrm{g}$ of atropine sulfate subcutaneously (s.c.) $30 \mathrm{~min}$ prior to induction of general anesthesia with $45 \mathrm{mg} / \mathrm{kg}$ pentobarbital sodium intraperitoneally (i.p.). A stainless steel screw electrode was threaded into the retroorbital bone to record the electrooculogram (EOG). Two electrodes, fashioned from Teflon-coated multistranded stainless steel wire, were implanted into the dorsal nuchal musculature to record the nuchal electromyogram (EMG). A pair of stainless steel screw electrodes were implanted bilaterally into the parietal bones to record the electroencephalogram (EEG). Two additional screw electrodes were implanted: (1) dorsal to the mastoid sinus and in contact with the temporalis muscle to serve as a ground electrode and (2) into one of the frontal sinuses to serve as the second electrode for EOG recording.

For the study of single-unit activity, 14 microelectrodes (diameters of 32 and $61 \mu \mathrm{m}$ ) were made from Formvar-insulated nichrome wire. These were passed as two bundles through a stereotaxically implanted microdrive, consisting of two screw-driven inner cannulas (23 gauge) that could be raised or lowered within two guide cannulas (19 gauge). The proximal tip of the anterior inner cannula was positioned above the NRO (15 posterior, AP $-9.0 \mathrm{~mm}$, ML $0.0 \mathrm{~mm}$, DV $10.0 \mathrm{~mm}$ ) (Heym et al., 1982). After the microdrive was secured to the skull with dental acrylic, the microelectrode bundles were lowered until the bundles extended $6.5 \mathrm{~mm}$ beyond the cannula tips. Microwires were glued to the inner cannulas. All electrodes were soldered to a 25-pin Amphenol connector that was then secured to the skull using dental acrylic.

In each cat a venous catheter was inserted into the right external jugular vein using a cutdown approach. This catheter and its threeway stopcock were then secured to the headpiece with dental acrylic.

Postoperatively, all cats received benzathine penicillin $(300,000 \mathrm{U}$, i.m.) and were housed in a heated recovery booth until fully alert, usually 1-2 d after surgery. For the first postoperative week, cats were given $63.5 \mathrm{mg}$ of amoxicillin/clavulinic acid orally twice daily. Intravenous lines were flushed weekly with heparinized saline (1000 $\mathrm{U} / \mathrm{ml})$.

\section{Electrophysiological recording procedures}

During a 2 week postoperative-recovery period, cats were habituated to the recording chamber, an electronically shielded, illuminated, soundattenuated booth $(65 \times 65 \times 95 \mathrm{~cm})$. All trials other than the treadmillinduced locomotor trials (described below) were conducted with the cat in the recording chamber.

Electrical contact by way of the Amphenol connectors allowed electrical potentials to pass through a counter-weighted cable system. This system included a 24-channel slip ring assembly (Airflyte Electronics Co., Bayonne, NJ). Electrical signals were amplified (Grass 7P511 AC) and band-pass filtered at $1-35 \mathrm{~Hz}$ (EEG), 1-60 Hz (EOG), 30-90 Hz (nuchal EMG) and $250-3000 \mathrm{~Hz}$ (unit activity).

Neuronal activity was monitored on a storage oscilloscope. If isolated (single unit) activity was present, the action potential was evaluated. For all isolated cells with action potential durations $\geq 2 \mathrm{msec}$, the study protocol would commence. Previous studies have detcrmined that a rather specific feature of serotonergic neurons, when compared to other neurons within raphe regions, is that such neurons have action potential durations $\geq 2$ msec (Heym et al., 1982; McCall and Clement, 1989). If no isolated unit activity meeting this criterion was observed, the microwires were advanced $40-80 \mu \mathrm{m}$ ventrally This screening process was repeated at $2 \mathrm{hr}$ intervals, two to four times daily, until isolated activity was identified or until the ventral surface of the medulla was reached, as indicated by the loss of background neuronal activity.

Potentials from isolated neurons with action potential durations of at least $2 \mathrm{msec}$ were distinguished from background activity by means of a time-amplitude window discriminator. Only recordings that displayed a signal-to-noise ratio greater than 3:1 were used in this study. Distinguished potentials were passed to an electronic counter from which a record of cell discharge activity was recorded polygraphically (Grass 7C) along with EEG, EOG, and EMG activity. All recording sessions occurred between 1100 and 2000 .

\section{Study protocols}

Isolated neuronal activity was studied during specific behavioral states, spontaneous behaviors (eating, grooming, and movement within the recording chamber), specific molor system challenges, and in response to administration of a specific 5- $\mathrm{HT}_{1 \mathrm{~A}}$ agonist.

Behavioral state protocol. The behavioral state conditions were as follows: (1) alert waking (AW) - the presence of a low-voltage desynchronized EEG coinciding with phasic nuchal EMG activity superimposed on tonic EMG activity, large and frequent eye movement potentials (>40/min), and a sitting or standing posture; (2) quiet waking (QW) - the presence of a desynchronized EEG, tonic EMG activity, a relative absence of phasic FMG activity, less frequent $(<40 / \mathrm{min})$ eye movements, and a recumbent or crouched posture; (3) SWS-largeamplitude synchronized EEG potentials, an absence of phasic EMG activity, intcrmittent small-amplitude eye movement potentials, and a recumbent posture; and (4) REMS-the presence of a low-voltage desynchronized EEG, bursts of rapid eye movement potentials, loss of tonic EMG activity, the presence of occasional phasic EMG activity, periodic body twitches, and a recumbent posture. The activity of each single unit with an action potential duration $\geq 2 \mathrm{msec}$ was recorded during all of the above defined behavioral states. For each neuron, 3 min samples of unit activity were obtained for each state prior to further experimentation.

Hypercarbic ventilatory challenge protocol. Carbon dioxide $\left(\mathrm{CO}_{2}\right)$ was administered into the recording chamber while continuously measuring the fraction of inspired $\mathrm{CO}_{2}\left(\mathrm{FICO}_{2}\right)$ (Puritan-Bennett capnograph, Bellmawr, NJ). Chamber air was continuously sampled through a Tygon tube $(1.0 \mathrm{~mm}$ i.d., $2.5 \mathrm{~m}$ length) positioned at the level of the cat's nares and connected to the inlet of the capnograph located outside the recording chamber. The lag time for detecting changes in $\mathrm{FICO}_{2}$ was $<1 \mathrm{sec}$. The $\mathrm{FICO}_{2}$ was raised at a rate of $1 \%$ every $1-2$ min, until an $\mathrm{FICO}$ of $8-10 \%$ was reached. Tenl-second epochs of unit activity were collected over a $3 \mathrm{~min}$ sample of QW and for at least 1 min at each percentage increase in $\mathrm{FICO}_{2}$. If unit activity increased by more than $20 \%$ at any $\mathrm{FICO}_{2}$ greater than $1 \%$, trials were first repeated in wakefulness to demonstrate reproducibility $(\leq 10 \%$ variability in responses at each $\mathrm{FICO}_{\text {, }}$, and were then repeated during SWS. To obtain an estimate of relative ventilatory movement during the challenge, a respiratory plethysmograph was secured around the cat's upper abdomen and on-line signals were recorded polygraphically. To minimize error in measurement, trials were rejected if the cat's body position was altered during the trial (Chadha et al., 1982). This method provides only a mcasure of changes in chest wall movement and does not indicate which respiratory muscles are activated.

Treadmill-induced locomotor challenge protocol. For 2-3 weeks prior to the locomotor trials, all cats were trained to walk and run on a $0^{\circ}$ incline treadmill. The treadmill was housed within a well-ventilated Plexiglas box positioned over a running surface of $90 \mathrm{~cm}$ long $\times 25$ $\mathrm{cm}$ wide. Treadmill speeds selected for training were $0.16,0.26,0.40$, $0.52,0.63,0.77$ and $0.85 \mathrm{~m} / \mathrm{sec}$. Attempts were made to have all cats run at each speed for at least $5 \mathrm{~min}$. A training log was kept and used to determine individually the speeds at which a given cat could maintain a constant pace for $5 \mathrm{~min}$. At least $30 \mathrm{~min}$ was allowed between completion of the hypercarbic trials and commencement of all locomotor trials. For the treadmill trials, cats were transferred from the recording chamber to the treadmill and reconnected with a flexible cable similar to the cable used for chamber recordings. Continuous polygraphic recordings were made throughout the treadmill trials. Trials were conducted at those speeds for which the subject had demonstrated a constant pace. Data were collected for 1 min at each speed studied; cats were allowed $1 \mathrm{~min}$ of rest between trials. Throughout the treadmill protocol, speeds were randomized and several speeds were repeated to demonstrate reproducibility ( $\leq 10 \%$ variability in unit responses at each given treadmill speed). 
Spontaneous feeding protocol. Feeding trials were conducted either $3 \mathrm{hr}$ before the hypercarbic trials or more than $1 \mathrm{hr}$ after the treadmill trials. Pureed meat and water $(50-100 \mathrm{ml})$ was presented to each cat. Unit activity was recorded for $5 \mathrm{~min}$ prior to food presentation, then for a 1-2 min period when the food was visible through the Plexiglas chamber door but inaccessible, throughout the spontaneous feeding episodes, and for 5 min after feeding. During food presentation, it is likely that olfactory cues were present as the Plexiglas door and chamber were not completely airtight.

\section{Determination of serotonin autoreceptor responsivity}

Following studies of behavioral states and of responses to the specified motor challenges, cells were studied for their responsiveness to a specific $5-\mathrm{HT}_{1 \mathrm{~A}}$ agonist, 8-hydroxy-2-(di- $n$-propylamino)tetralin (8-OH DPA' '). Suppression of cell firing after systemic administration of this agonist has previously been used to support the identification of medullary raphe neurons as serotonergic (McCall and Clement, 1989). In the anesthetized cat, serotonergic neurons have been distinguished from other medullary raphe neurons by meeting the following criteria: (1) regular patterns of discharge, (2) firing rates of 1-2 spikes/sec, 3) action potential durations $\geq 2 \mathrm{msec}$, and (4) a complete cessation of firing in response to systemic administration of low doses $(1-3 \mu \mathrm{g} / \mathrm{kg}$, i.v.) of $8 \mathrm{OH}$ DP $\Lambda \mathrm{T}$ (McCall and Clement, 1989). In the freely moving cat, however, cells with regular firing rhythms and action potential durations $\geq 2 \mathrm{msec}$ have average discharge firing rates of 4-5 spikes/sec (Heym et al., 1982), and their responsiveness to 8-OH DPAT has not been determined. The purpose of this protocol was to evaluate the responsiveness of presumed serotonergic NRO and NRP neurons to 8-OH DPAT. ( \pm )-8-OH DPAT hydrobromide (Research Biochemicals, Wayland, NY), dissolved in physiological saline, was administered intravenously if the central intravenous catheter was functioning; otherwise, the drug was administered subcutaneously. If given intravenously, progressive dosing (10-40 $\mu \mathrm{g} / \mathrm{kg})$ was performed until either a $\geq 70 \%$ suppression in firing rate was seen relative to the $\mathrm{AW}$ baseline prior to injection or until a maximum dose of $40 \mu \mathrm{g} / \mathrm{kg}$ was given. Intervals between doses were $>90 \mathrm{~min}$. If $40 \mu \mathrm{g} / \mathrm{kg}$ (i.v.) did not result in a $\geq 70 \%$ suppression in firing rate or if the intravenous was no longer functional, a subcutaneous dose of $250 \mu \mathrm{g} / \mathrm{kg}$ was administered. Cells were defined as 8 -OH DPAT responsive if the maximal dose resulted in a suppression in firing rate of greater than $50 \%$, for 1 min, within 5 min of intravenous administration or within $15 \mathrm{~min}$ of subcutaneous administration.

Using criteria determined from intracellular recordings of confirmed serotonergic cells (Aghajanian and VanderMaelen, 1982), we defined neurons as serotonergic cells if they demonstrated (1) action potential durations $\geq 2 \mathrm{msec}$, (2) regular firing patterns during QW, and (3) the lowest firing rates during REMS.

\section{Histology}

Cats were deeply anesthetized with sodium pentobarbital $(50 \mathrm{mg} / \mathrm{kg}$, i.p.), and direct anodal current at $20-40 \mu \mathrm{A}$ was passed for $10-20 \mathrm{sec}$ through individual microelectrodes to mark the sites from which neuronal recordings were obtained. Cats were then perfused intracardially with physiological saline followed by $10 \%$ formalin, and finally with $5 \%$ potassium ferrocyanide in formalin to produce a Prussian blue reaction at all electrically marked recording sites. Brains were stored in $10 \%$ formalin until frozen and sliced as $50 \mu \mathrm{m}$ coronal sections through the medulla. All sections were mounted and later stained with neutral red. Recording sites (blue spots) were located microscopically. Only cells found to be localized within NRO and NRP (Taber et al., 1960; Jacobs et al., 1984) were included in this study.

\section{Data analysis}

The overall purpose of our data analysis was to determine if unit activity for NRO and NRP neurons was differentially affected by behavioral state, spontaneous behaviors, hypercarbia, and/or locomotor speed. For those units proving to be differentially affected, data analysis was extended to include comparison of individual means for significance and to determine (for the latter two challenges) to what degree that variable condition shows interrelationships with the levels of challenge in a given population. Data were further analyzed for differences in responses between those NRO and NRP neurons defined as 8-OH DPAT responsive and unresponsive.

The behavioral state data were analyzed for differences across sleep-wake states using a repeated-measures analysis of variance (ANOVA). Firing rates were calculated as mean values of unit activity (spikes/sec) for all $10 \mathrm{sec}$ epochs within each $3 \mathrm{~min}$ sample. Unless stated otherwise, all data are reported as mean values \pm SEM. A variance stabilizing transformation of the data (square root of the mean) was implemented because the standard errors appeared proportional to the mean values and because this analysis was of Poisson data (i.e., data per unit time). Univariate procedures were performed to analyze behavioral state differences in mean unit activity. A between-subjects factor analysis of 8-OH DPAT responsiveness was performed. The Huynh-Feldt correction for state and group by state was used to account for unequal covariances. Paired $t$ tests with Bonferroni corrected $p$ values were performed to indicate which sleep states had differing mean firing rates.

For the hypercarbia data, 1 min sampling periods of $10 \mathrm{sec}$ epochs were used to determine the mean unit activity for each $\mathrm{FICO}_{2}$ level. Individual neuronal responses to $\mathrm{CO}_{2}$ challenge were analyzed first for strong interrelationships (correlation coefficients $>0.70$ ). Such neurons were defined as $\mathrm{CO}_{2}$ responsive. To further characterize the shapes of the response curves, $\beta$-coefficients were determined for both the linear and quadratic components of each response curve simultaneously. MANOVA was then used to jointly test the significance of the linear and quadratic components. In this model, the null hypothesis was that the linear and quadratic $\beta$-coefficients were simultaneously equal to zero. To compare $\mathrm{CO}_{2}$ responsiveness in SWS to that seen in QW, neuronal responses (percentage of baseline firing rate) and response rates (change in firing rate/change in $\mathrm{FICO}_{2}$ ) were determined during both behavioral states at comparable levels of inspired $\mathrm{CO}_{2}$ Student's paired $t$ test was used to determine state dependency in neuronal response rates to $\mathrm{CO}_{2}$, and the $95 \%$ confidence intervals for the true slope were used to determine whether the unit response curves in SWS were significantly different from zero. To determine if significant relationships existed between unit activity and ventilatory motor output, unit activity and plethysmographic data (relative minute ventilation, relative tidal volume and respiratory frequency) were analyzed using linear regression. Relationships were determined for QW conditions.

To determine if the firing patterns of hypercarbia-responsive neurons were respiratory related, we used previously described methods of analysis (Netick and Orem, 1981). For this analysis, we determined firing frequencies during 10 phases of the respiratory cycle and analyzed the firing frequency for each phase for differences using ANOVA. We analyzed 50 breaths in QW obtained during baseline levels of inspired $\mathrm{CO}_{2}\left(\mathrm{FICO}_{2}=0.00\right)$ and hypercarbic conditions $\left(\mathrm{FICO}_{2}=0.05-0.08\right)$ for respiratory-related activity.

The locomotor challenge data were analyzed using statistical methods outlined above for the hypercarbic challenge data using all $10 \mathrm{sec}$ epochs within 1 min sampling periods at each treadmill speed. These data were analyzed individually in relationship to treadmill speed (linear correlation) and response pattern (MANOVA).

For the feeding trials, data were analyzed for the $120 \mathrm{sec}$ of AW baseline preceding the feeding trial, $60 \mathrm{sec}$ during inaccessible food presentation, the first $50 \mathrm{sec}$ of feeding, the last $10 \mathrm{sec}$ of feeding, and the $300 \mathrm{sec}$ following spontaneous cessation of feeding. To determine feeding responsiveness, ANOVA was performed on each cell. Cells were defined as feeding-responsive neurons if ANOVA revealed a significant change in activity that was $\geq 20 \%$ of AW baseline levels. Feeding-responsive neurons were analyzed as a group using ANOVA

\section{Results}

The effects of 8-OH DPAT on waking firing rates of NRO and NRP neurons

Single-unit activity was recorded for 30 cells meeting all criteria to be defined as serotonergic neurons and later confirmed histologically to be within the NRO or NRP. Examples of an action potential and of a spike train for the same cell are shown in Figure 1. Of these 30 cells, 28 were tested with 8-OH DPAT. For 15 of these neurons, data were obtained before and after intravenous administration of 8-OH DPAT ( 10 or $20 \mu \mathrm{g} / \mathrm{kg}$ ). The mean percentage reduction in firing rates produced by $8-\mathrm{OH}$ DPAT (both doses analyzed together) for all 15 cells studied was $68.9 \pm 7.0 \%(p<0.0001)$. The range of percentage re- 

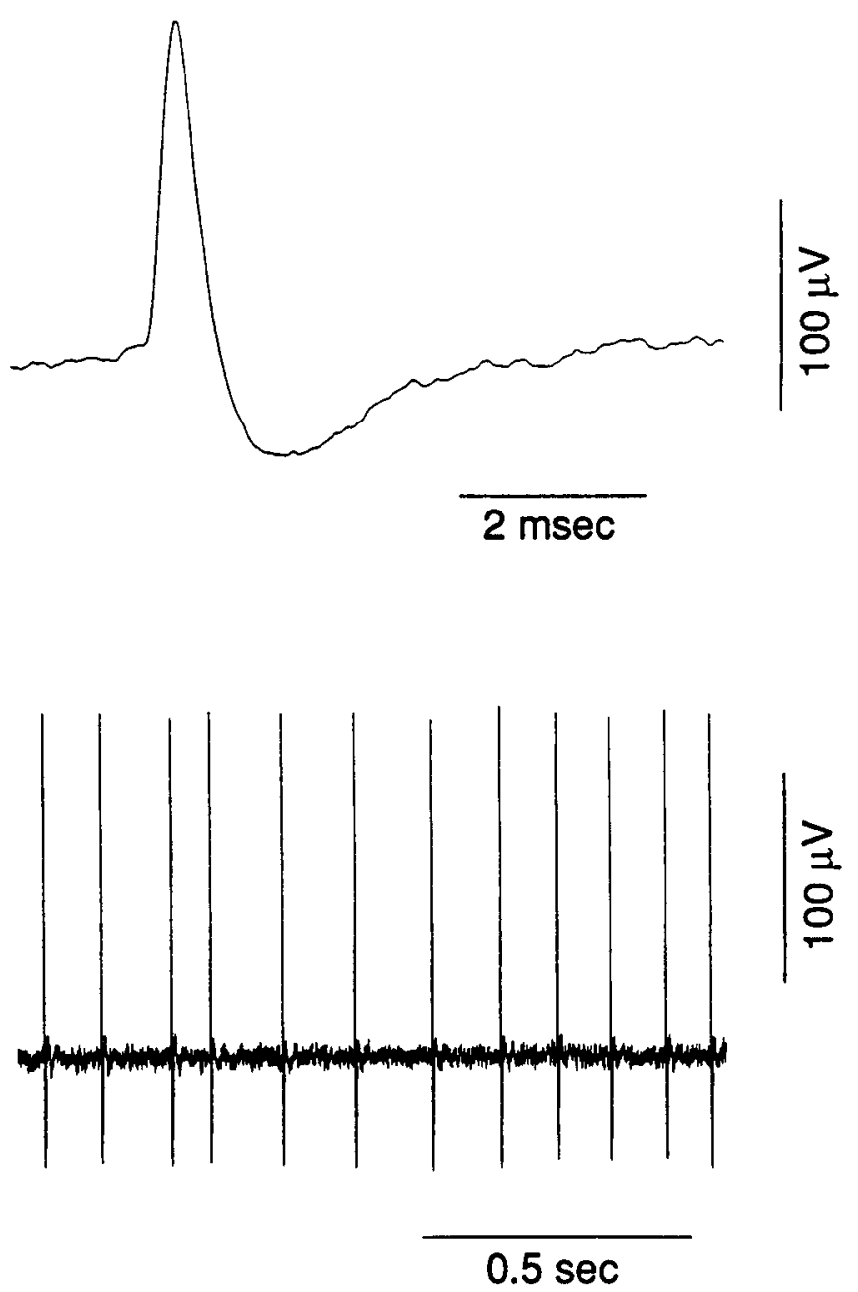

Figure 1. Computer-generated images of digitized data showing a single-action potential (top) and a spike train (bottom) recorded from a serotonergic NRP neuron in an alert, freely moving cat.

duction was $29.3-100 \%$, with only 3 of 15 cells showing complete suppression in firing for at least $1 \mathrm{~min}$. Individually, 12 of the 15 neurons were defined as 8-OH DPAT responsive serotonergic neurons (see Materials and Methods). For 15 neurons, firing rate data were obtained after subcutaneous administration of $250 \mu \mathrm{g} / \mathrm{kg}$ of $8-\mathrm{OH}$ DPAT. Although two neurons are shared by both groups (i.e., intravenous and subcutaneous routes of administration), the mean baseline firing rate for the group of cells that received subcutaneous injections was higher than that for the group receiving intravenous injections $(6.27 \pm 0.43$ vs $34.13 \pm 0.55$ spikes $/ \mathrm{sec}, p<0.025$ ). The group receiving 250 $\mu \mathrm{g} / \mathrm{kg}$ 8-OH DPAT (s.c.) demonstrated a mean reduction in firing rate of $52.0 \pm 8.4 \%(p<0.0001)$. The range of suppression for this group was $4.9-100 \%$, with two cells demonstrating complete suppression of neuronal activity. From this group, seven additional neurons were defined as $8-\mathrm{OH}$ DPAT responsive. Thus, of the 28 presumed serotonergic neurons tested with $8-\mathrm{OH}$ DPAT, 19 were responsive to the drug. For both groups there was a statistically significant inverse relationship between baseline AW firing rates and the percentage of decrease in neuronal activity after $8-\mathrm{OH}$ DPAT $(10$ and $20 \mu \mathrm{g} / \mathrm{kg}$, i.v.: $r=-0.64$ and -0.66 , respectively, $p<0.05 ; 250 \mu \mathrm{g} / \mathrm{kg}$, s.c: $r=-0.69, p<$ $0.0025)$.

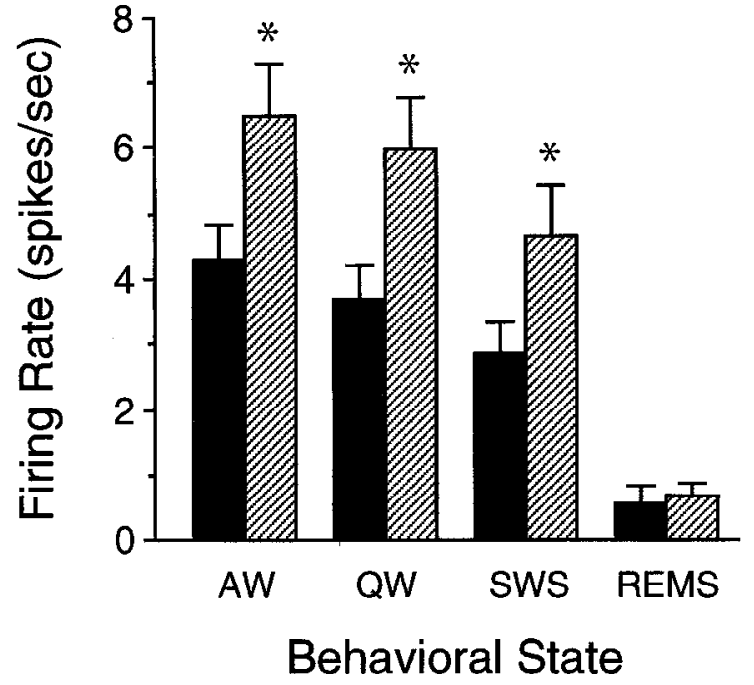

Figure 2. Mean $( \pm \mathrm{SEM})$ firing rates for $8-\mathrm{OH}$ DPAT responsive $(n$ $=19 ;$ solid columns $)$ and unresponsive $(n=9 ;$ hatched columns $)$ caudal raphe serotonergic neurons across behavioral states. $A W$, alert waking; $Q W$, quiet waking; $S W S$, slow-wave sleep; $R E M S$, rapid-eye-movement sleep. Asterisks $\left(^{*}\right)$ denote significant $(p<0.025)$ differences in firing rates within a given behavioral state.

\section{The effects of behavioral state on neuronal activity in NRO and NRP}

The influence of behavioral state on neuronal activity was studied for 33 cells with action potentials $\geq 2 \mathrm{msec}$. Three of these cells displayed irregular firing rates; these cells demonstrated either no change across behavioral states $(n=2)$ or a slight increase in firing rate during REMS $(n=1)$. Thirty neurons with action potential durations $\geq 2 \mathrm{msec}$ demonstrated regular discharge patterns, suppression of neuronal activity during REMS by $>60 \%$ of AW baseline levels, and lowest firing rates during REMS. For these neurons, the spontaneous firing rates in QW ranged from 0.9 to 12.7 spikes/sec. The group mean firing rates for each behavioral state were as follows: AW, $5.47 \pm$ 0.49 spikes/sec; QW, $4.81 \pm 0.47$ spikes/sec; SWS, $3.80 \pm 0.41$ spikes/sec; and REMS, $0.55 \pm 0.13$ spikes/sec. There were signiticant differences in unit activity across behavioral states $(p<$ 0.0002). Comparisons between states (using transformed data) showed that firing rates during SWS were significantly reduced from both $\mathrm{AW}$ and $\mathrm{QW}(p<0.05)$. REMS firing rates were significantly reduced from AW, QW, and SWS $(p<0.001)$. The mean percentage decrease in firing rates from AW to REMS was $79.3 \pm 3.0 \%$ (range, 63.7-100\%). During REMS, neuronal activity was completely suppressed for 8 of the 30 cells. When cells are distinguished as 8-OH DPAT responsive $(n=19)$ and unresponsive $(n=9)$ and then compared for differences in mean firing rates for each behavioral state, higher firing rates were found for the 8-OH DPAT unresponsive cells in AW $(p<$ 0.001 ), QW ( $p<0.001)$, and SWS $(p<0.025)$. During REMS, however, there were no significant differences in firing rates between the two groups. These data are summarized in Figure 2.

\section{NRO and NRP unit activity during feeding}

The activity of 29 presumed serotonergic cells was studied in relation to spontaneous feeding. No cells were activated during exposure to inaccessible food. During feeding, however, 12 of the 29 cells tested demonstrated significant increases in firing rate as analyzed by individual ANOVA, and the mean firing 


\section{Type I Feeding Response}

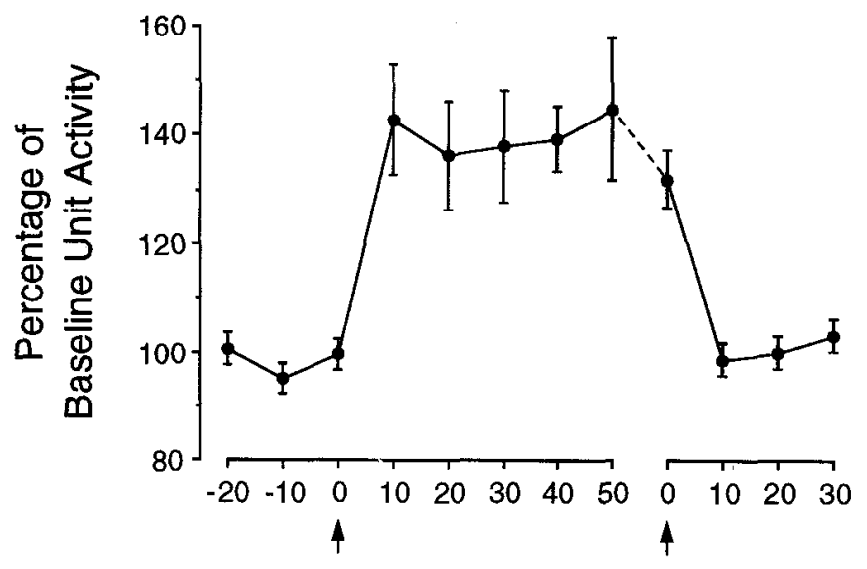

Type II Feeding Response

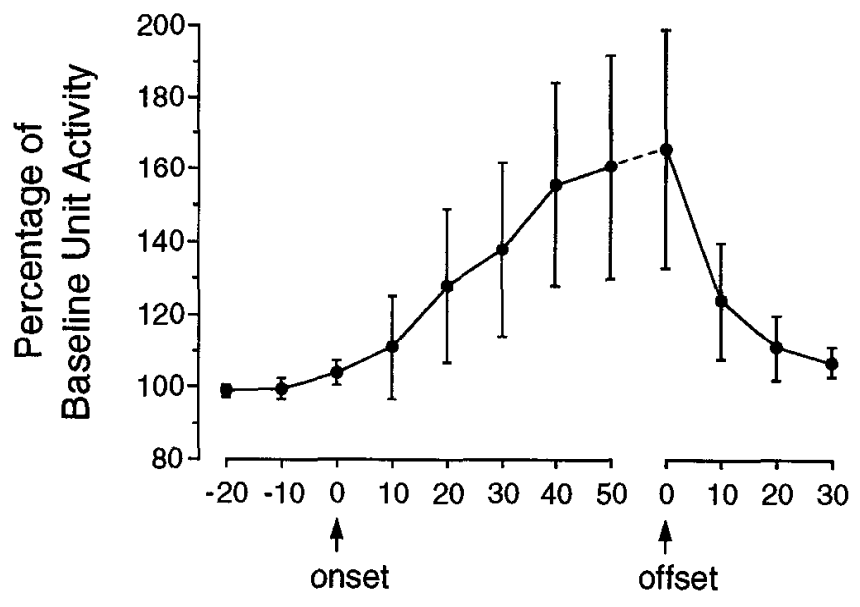

Time (sec) Relative to Feeding

Figure 3. Two patterns of neuronal activation of caudal serotonergic cells in relation to spontaneous feeding. Top, Response pattern for the nine cells demonstrating significant increases in activity temporally related to the onset and offset of ingestive behaviors (type I feeding response). Unit activity was significantly increased from baseline levels throughout the entire feeding episode $(p<0.05)$. Bottom, Data for three neurons that demonstrated a gradual increase in activity relative to feeding onset and a gradual decline in activity upon termination of feeding (type II feeding response). Results are presented as means \pm SEM.

rates during feeding were increased by more than $20 \%$ from AW baseline levels. Thus, these 12 cells qualified as feeding-responsive neurons. ANOVA revealed two distinct patterns of feeding responses. For 9 of the 12 feeding-responsive neurons, this increase occurred coincident with feeding onset $(p<0.05)$ and was maintained tonically throughout the feeding period. Unit activity abruptly returned to baseline levels coincident with cessation of eating (type I feeding response). The mean increase in unit activity during feeding relative to baseline nonfeeding was $38.8 \pm 1.9 \%(p<0.01)$. The data for the nine cells demonstrating this feeding response pattern are shown in Figure 3 (top). In contrast to the abrupt increase in activity during feeding observed for the nine cells above, the remaining three cells dem-

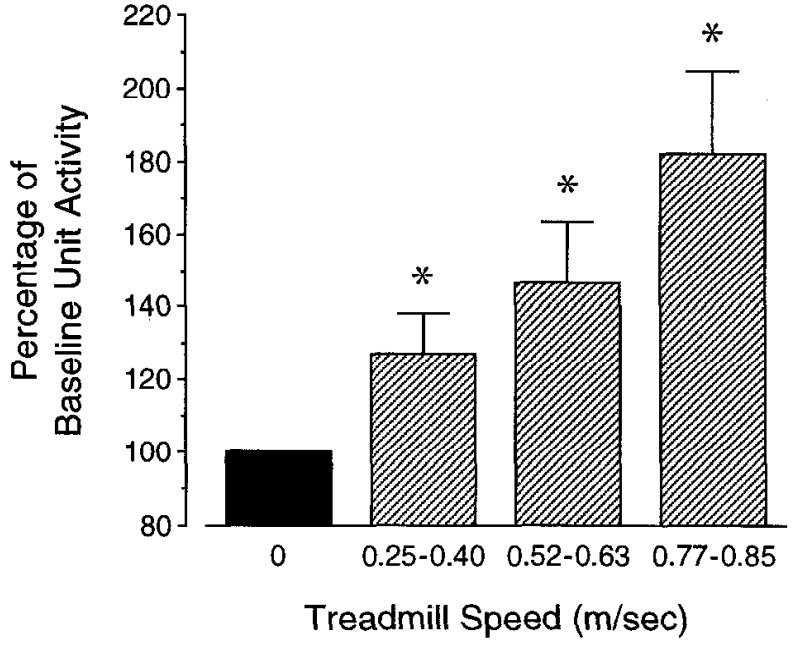

Figure 4. Activation of caudal raphe serotonergic neurons during treadmill-induced locomotion. Data are presented for the 12 neurons tested at all three groups of treadmill speeds (hatched columns). Results are means \pm SEM. Asterisks $\left(^{*}\right)$ denote significant $(p<0.05)$ increases in unit activity relative to stationary prelocomotion values.

onstrated gradual increases in unit activity during feeding. Neuronal responses reached a plateau 60-80 sec after feeding onset (type II feeding response; Fig. 3, bottom). In addition, the activity of these cells gradually returned to baseline levels over the next $30-240 \mathrm{sec}$ following the cessation of feeding. For these three cells collectively, the largest percentage increase from baseline levels occurred during the 60-70 sec epoch after feeding onset $(66.4 \pm 33.7 \%)$. The two subgroups of neurons responsive to feeding were composed of both 8-OH DPAT responsive and unresponsive neurons.

\section{The effects of treadmill-induced locomotion on neuronal activity}

Treadmill-induced locomotor trials were successfully completed for 24 presumed serotonergic NRO and NRP neurons. As a group, there were significant differences across treadmill speed conditions $(p<0.0002)$. Unit activity was significantly elevated $(p<0.05)$ from baseline levels by $27.1 \pm 10.8 \%$ at speeds of $0.25-0.40 \mathrm{~m} / \mathrm{sec}$, by $46.4 \pm 17.0 \%$ at speeds of $0.52-0.63$ $\mathrm{m} / \mathrm{sec}$, and $81.8 \pm 22.7 \%$ at speeds of $0.77-0.86 \mathrm{~m} / \mathrm{sec}$. Data for the 12 cells studied during all three speed conditions are summarized in Figure 4.

Individually, 21 of the 24 cells tested demonstrated significant positive linear relationships between unit activity and treadmill speed ( $r$ range, 0.72-1.00; mean $r=0.90 \pm 0.02$; all individual correlation coefficient values were significant, $p<0.001$ ). Two cells demonstrated no relationship between unit activity and treadmill speed ( $r$ values $=0.07$ and -0.10 ); the remaining cell demonstrated a strong negative relationship $(r=-0.86, p<$ 0.01 ; maximum decrease in unit activity $=40.6 \%$ ). For the 21 cells showing significant positive relationships between treadmill speed and unit activity, a multiple linear regression was fitted for each cell separately. This analysis showed a strong negative relationship between the linear and quadratic components (group $r--0.79, p<0.002$ ). Not all cells showed the same pattern of activation with respect to increases in treadmill speed. For purposes of clarifying these differences, cells were classified into one of three response categories: (1) responses saturate as treadmill speed is increased, high $\beta$-linear and low $\beta$-quadratic com- 
High $\beta$-linear, Low $\beta$-quadratic Response Pattern

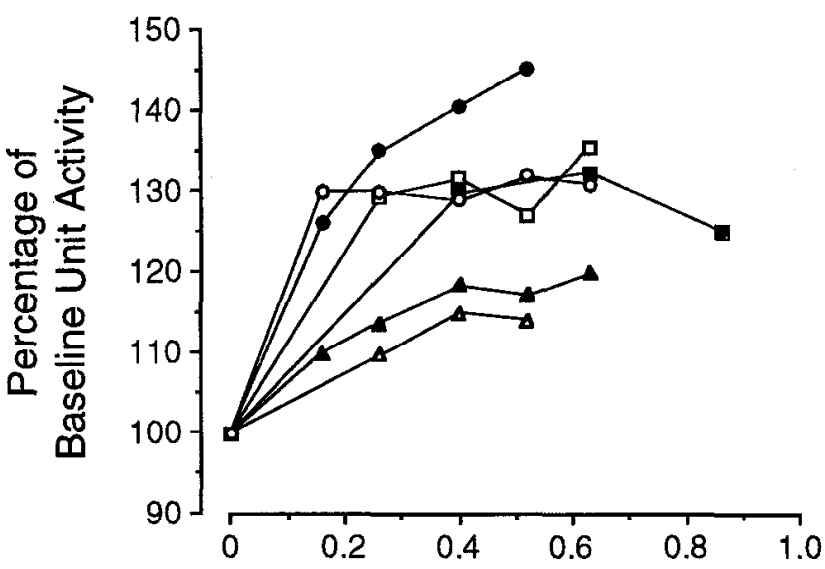

\section{Low $\beta$-linear, High $\beta$-quadratic} Response Pattern
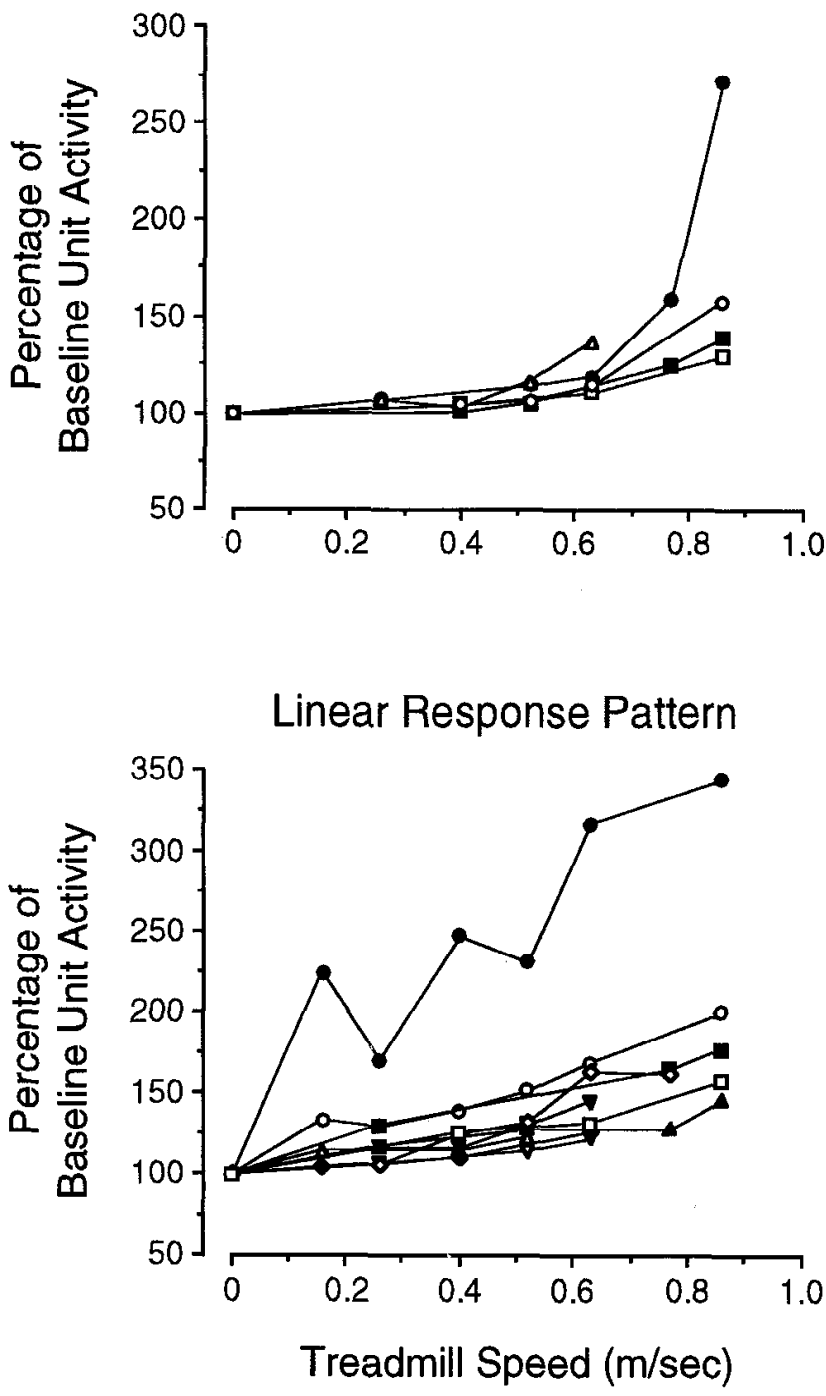

Figure 5. Three patterns of neuronal activation during treadmill-induced locomotion. Individual neuronal responses fell into one of three ponents: $\beta$-lin $\geq \beta$-quad +5 ; (2) a high threshold of speed for activation, low $\beta$-linear and high $\beta$-quadratic components: $\beta$-lin $\leq \beta$-quad-5; and (3) a relatively limear increase in activity: $\beta$ quad-5 $<\beta$-lin $<\beta$-quad +5 . This analysis does not purport to show, however, that these cells belong to distinct subgroups rather than being part of a continuum. Data on the neurons displaying these three response patterns are shown in Figure 5. Patterns of response to treadmill-induced locomotion are indistinguishable for 8-OH DPAT-responsive and-unresponsive neurons, as both groups of neurons are represented in all three patterns of response.

For the majority of the 21 cells showing increased firing rates during treadmill-induced locomotion, unit activity remained tonically activated throughout the locomotor trials. For four of these neurons, however, unit activity increased with locomotion but the discharge pattern became less regular. One of these neurons showed increased discharge in phase with the step cycle. Examples of a typical tonically increased unit response and of the phasically increased neuronal activity are shown in Figure 6 .

The excitatory neuronal response to treadmill locomotion was coincident with the onset of the treadmill and remained stable for a given speed. Unit activity returned immediately to, or just below, baseline levels when the treadmill was stopped; mean unit activity for the first $10 \mathrm{sec}$ epoch postexercise was $95.3 \pm$ $3.3 \%$ of baseline values $(n=21)$.

The effects of hypercarbic ventilatory challenges on neuronal activity

Twenty-seven NRO and NRP presumed serotonergic neurons were tested for responsiveness to hypercarbic ventilatory challenge. The majority of neurons studied ( 21 of 27 ) did not display significant changes in firing rates in response to increased levels of inspired $\mathrm{CO}_{2}$. For these neurons, the mean correlation coefficient for the relationship between firing rate and $\mathrm{FICO}_{2}$ was $0.19 \pm 0.05$ ( $p=0.39$; range, 0.09 to 0.52$)$. In contrast, a subset of the neurons studied (6 of 27 ) responded significantly to the hypercarbic challenge. These neurons displayed strong positive relationships between unit activity and $\mathrm{FICO}_{2}$ (mean $r$ values, $0.84 \pm 0.02 ; p<0.001$; range, $0.81-0.91$ ). To further substantiate the significance of neuronal responses to hypercarbia, individual ANOVA's were performed on unit activity data for the six hypercarbic-responsive neurons across all $\mathrm{FICO}_{2}$ levels. For all six neurons, differences were highly significant $(p<$ 0.004).

Figure 7 (left) presents data for all $\mathrm{CO}_{2}$-responsive neurons and illustrates that not all cells respond to hypercarbia in the same fashion. Five of the six neurons (cells 1, 4, 11, 14, 22) were responsive to 8-OH DPAT. Analysis of the six hypercarbic-responsive neurons revealed that the group threshold $\mathrm{FICO}_{2}$ level for which a significant percentage increase in unit activity occurred was $3 \%(p<0.025)$. The group ncuronal response as a function of $\mathrm{FICO}_{2}$ is shown in Figure 7 (right).

As an indirect measure of ventilatory motor output, respiratory plethysmography was successfully implemented during hypercarbic challenges for three of the six cells studied ( $n=$

$\leftarrow$

defined linear-quadratic relationships (see Results). Top, Neuronal responses for those cells $(n=6)$ with high $\beta$-linear and low $\beta$-quadratic components. Middle, Neuronal responses for those cells $(n=5)$ with low $\beta$-linear and high $\beta$-quadratic components. Bottom, Neuronal responses for those cells $(n=9)$ displaying a selective linear response. 
Tonic Response
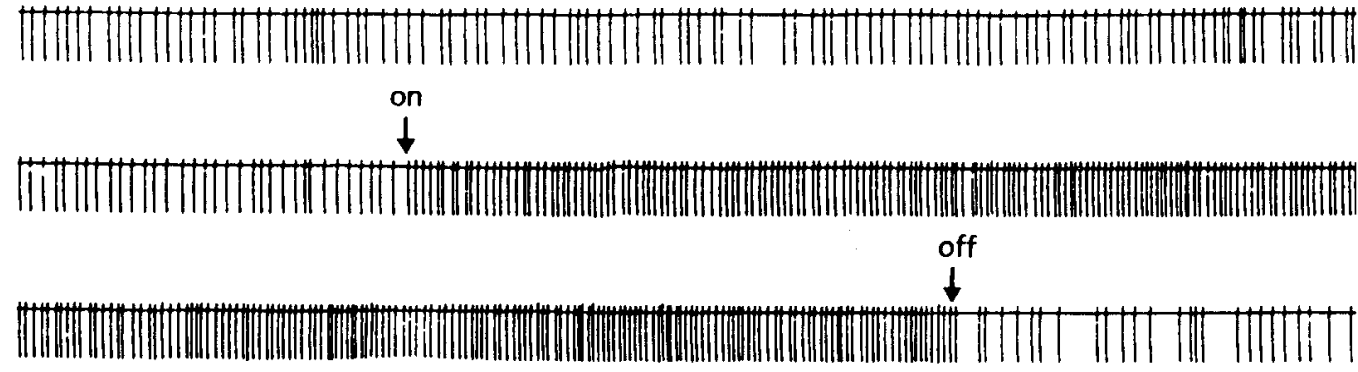

$10 \mathrm{sec}$

\section{Phasic Response}

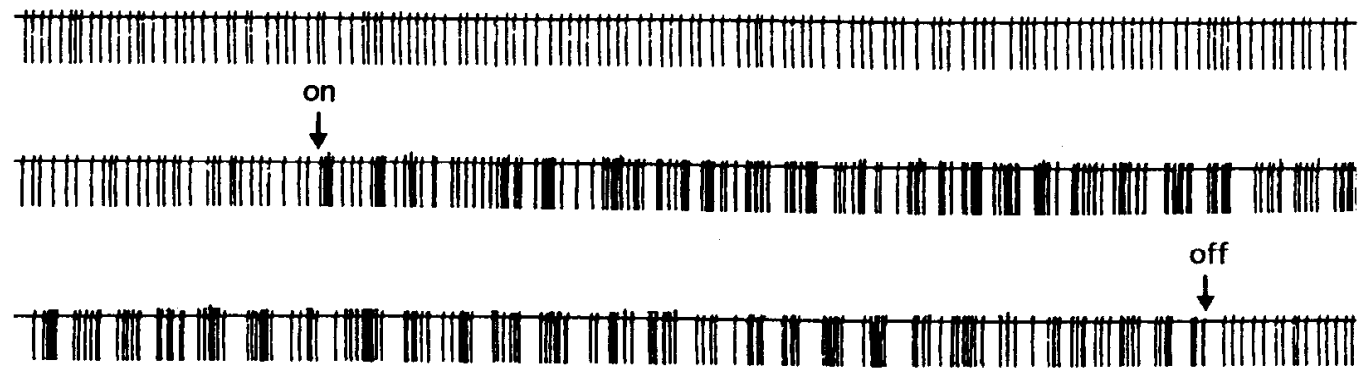

$10 \mathrm{sec}$

Figure 6. Discharge patterns of serotonergic caudal raphe neurons in response to treadmill-induced locomotion. Polygraphic event mark traces of unit activity are shown for two neurons. Upper traces display the activity of a cell that was tonically activated during locomotion. Note the decreased unit activity following cessation of locomotion. Lower traces show a phasic firing pattern that was temporally related to the step cycle during locomotion. Arrows indicate the onset and offset of locomotion. During both of these trials, the treadmill speed was $0.86 \mathrm{~m} / \mathrm{sec}$.
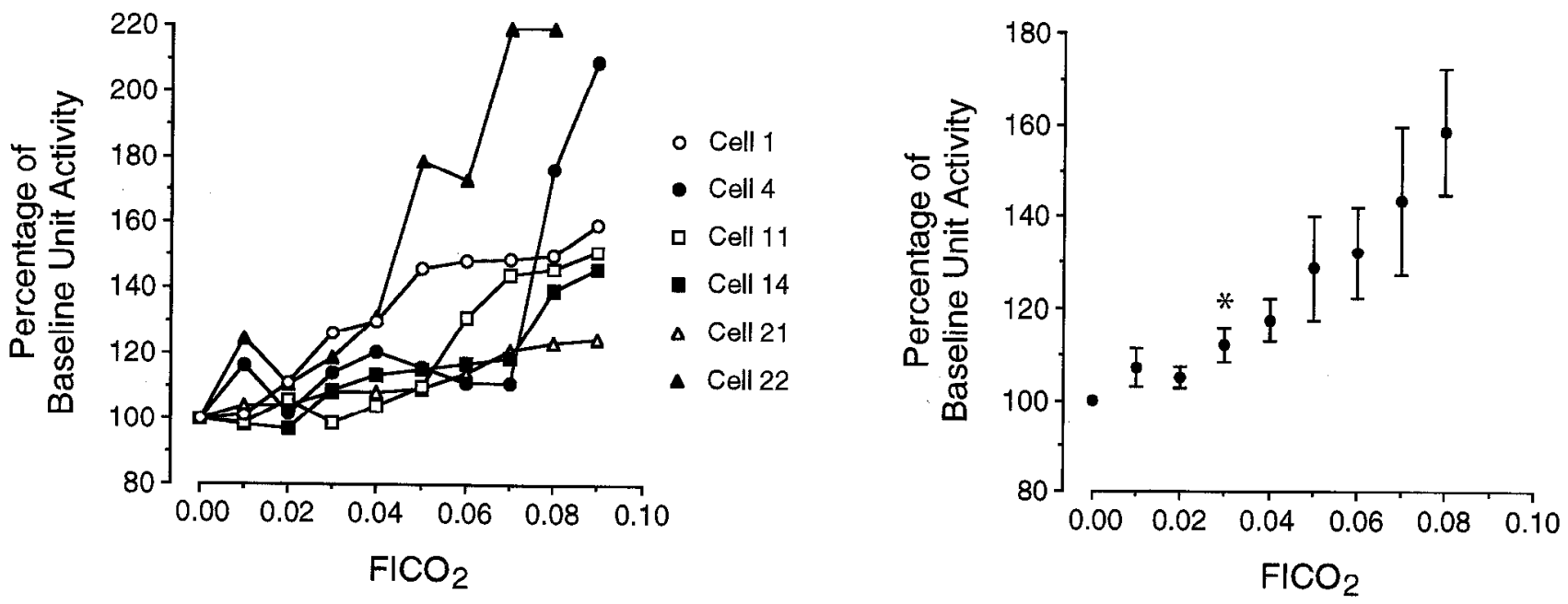

Figure 7. Response patterns for serotonergic neurons to the fraction of inspired $\mathrm{CO}_{2}\left(\mathrm{FICO}_{2}\right)$ for the six cells responsive to hypercarbic ventilatory challenge (mean 1 SEM). Left, Individual response patterns. Right, Group response pattern. The asterisk $\left({ }^{*}\right)$ marks the lowest FICO ${ }_{2}$ for which unit activity is significantly $(p<0.025)$ increased from baseline waking levels. These data suggest a threshold FICO for group neuronal activation at 0.03 . 


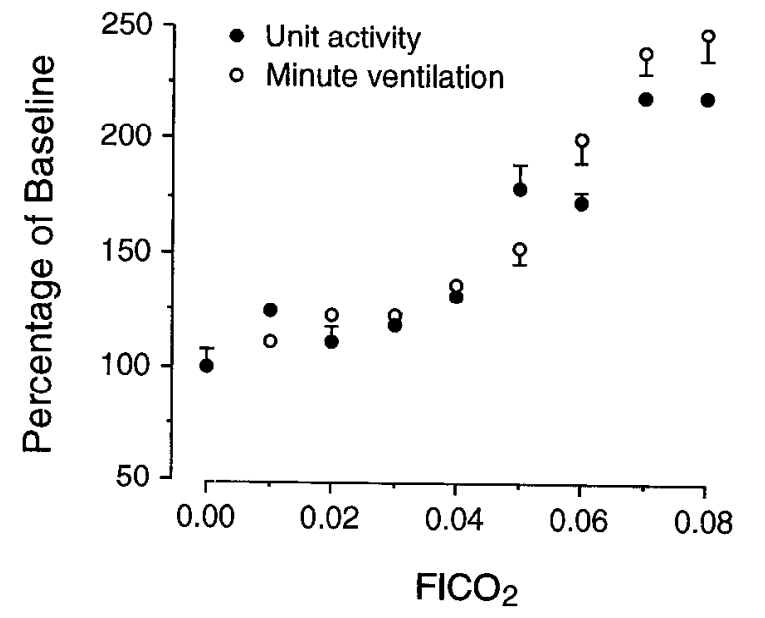

Figure 8. Relationships between the activity of a single serotonergic caudal raphe neuron and minute ventilation both as a function of the fraction of inspired $\mathrm{CO}_{2}\left(\mathrm{FICO}_{2}\right)$ : parallel increases in unit activity and minute ventilation during progressive increases in $\mathrm{FICO}_{2}$. Positive SEM bars are shown for unit activity data, and negative SEM bars are shown for minute ventilation.

3 cats). Minute ventilation was estimated from the plcthysmographic recording using the formula (mean peak amplitude of chest wall movement) $\times$ (breaths $\cdot \mathrm{min}^{-1}$ ). Consistent with previous reports (Santiago et al., 1981), cats demonstrated strong positive linear responses in minute ventilation to incremental increases in $\mathrm{CO}_{2}$ tension $(r=0.96 \pm 0.02, p<0.001)$. For these neurons, there is a strong positive relationship between unit activity and minute ventilation $(r=0.90 \pm 0.03$, $p<0.001)$. A similar positive linear relationship is seen between unit activity and chest wall movement $(r=0.88 \pm 0.02$, $p<0.001$ ); while a very weak relationship exists between unit activity and respiratory rate $(r=-0.17 \pm 0.27, \mathrm{NS})$. Respiratory rate varied little throughout the hypercarbic challenges. An example of the parallel unit and minute ventilation responses to increasing inspired $\mathrm{CO}_{2}$ concentrations is shown in Figure 8 for cell 22 .

Four of the six neurons responsive to hypercarbic challenge in wakefulness were further studied for their response to increases in $\mathrm{FICO}_{2}$ during SWS. All four cells demonstrated reduced responsiveness to hypercarbia during sleep. Figure 9 compares waking and SWS unit responses to hypercarbia for each of the four cells. The slopes of the response curves were significantly lower in SWS than in QW: $0.22 \pm 0.12$ spikes/ sec per 0.05 increase $\mathrm{FICO}_{2}$ versus $1.07 \pm 0.05$ spikes $/ \mathrm{sec}$ per 0.05 increase $\mathrm{FICO}_{2}(p<0.005)$. For two of these cells $(21$ and 22), the slopes of the response curves during SWS were not significantly different from zero, indicating no response to $\mathrm{CO}_{2}$. The mean percentage increase in unit activity from $\mathrm{FICO}_{2}$ 0.00 to 0.05 was also significantly lower in SWS than in QW: $13.0 \pm 2.7 \%$ increase versus $32.6 \pm 12.6 \%$ increase $(p<$ $0.05)$. The reduction in unit responsiveness from waking to SWS was paralleled by a similar $(60 \%)$ though statistically nonsignificant reduction in the hypercapnic ventilatory response in SWS $(216.1 \pm 61.1 \%$ vs $383.4 \pm 21.3 \% ; p<0.10$, $n=3$ cats).

To determine if the six cells responsive to hypercarbic challenge were respiratory related units (RRUs), the relationship between respiratory activity and cell firing pattern was determined as described in Materials and Methods (Data analysis). Wake- fulness data were analyzed separately for normocarbic and hypercarbic conditions. Under both conditions, the firing patterns were not related to a respiratory phase. ANOVA found no significant relationship between cell firing frequency and one or more phases of the respiratory cycle $(p=0.25$ and $p=0.54$ for baseline and hypercarbic conditions, respectively). Consequently, $\epsilon^{2}$ values were not performed.

\section{NRO and NRP unit activity during spontaneous motor behaviors}

Neuronal activity for the 30 cells meeting our criteria for presumed serotonergic neurons was studied during spontaneous movement within the recording chamber. Nine of the 30 neurons demonstrated increased activity (greater than $40 \%$ of the AW baseline levels) lasting 2-5 sec in association with spontaneous movements. The specific spontaneous movements were neck extension, moving from a crouched position to standing or from standing to crouching, and limb movements (stretching and digging). Only one of these activities was associated with increased firing of a particular cell. Similar findings have previously been reported (Heym et al., 1982). Although increases were consistently observed with spontaneous movements, neuronal activation could not be elicited with passive movement of the head or limbs.

\section{Responsiveness to multiple motor challenges}

Presumed serotonergic neurons were analyzed for responsiveness to multiple motor tasks. These data are summarized in Figure 10 . Of the 21 cells showing increased activity during treadmill-induced locomotion (Fig. 10, top), 19 were tested with hypercarbia, and six of the 19 were also responsive to hypercarbia. All of the 21 locomotor-responsive cells were tested during feeding, and 9 of the 21 cells were responsive to feeding; eight demonstrated a type I feeding response and one cell a type II response.

All six hypercarbia-responsive cells (middle) responded to locomotor challenge. These cells were evenly distributed among the three locomotor response patterns. Four of the six hypercarbia-responsive cells responded to feeding; all of these cells were type I feeding cells.

Nine cells displayed a type I feeding response. Eight of these cells were tested for treadmill response and were responsive to locomotor challenge. The same eight cells were tested with hypercarbia, and four of the eight cells were responsive to hypercarbia.

Only three cells tested with feeding showed a type II feeding response. Of these cells, only one neuron showed increased activity with locomotion; one cell showed decreased activity, and one cell showed no change in firing rate. Two of the three type II cells were studied during hypercarbia, and neither cell responded to this manipulation. Therefore, neither of the two cells studied with all three challenges responded positively to another challenge. The feeding data are shown as a group (types I and II) in the bottom panel of Figure 10.

A total of 19 cells were studied during all three challenges; 10 of the 19 cells were responsive to two or more challenges, and 4 of these 19 cells were responsive to all three challenges.

\section{Histological localization of recording sites}

All 30 cells meeting electrophysiological and behavioral state criteria for presumed serotonergic neurons were located within $500 \mu \mathrm{m}$ of the midline in the regions of serotonergic cell bodies 

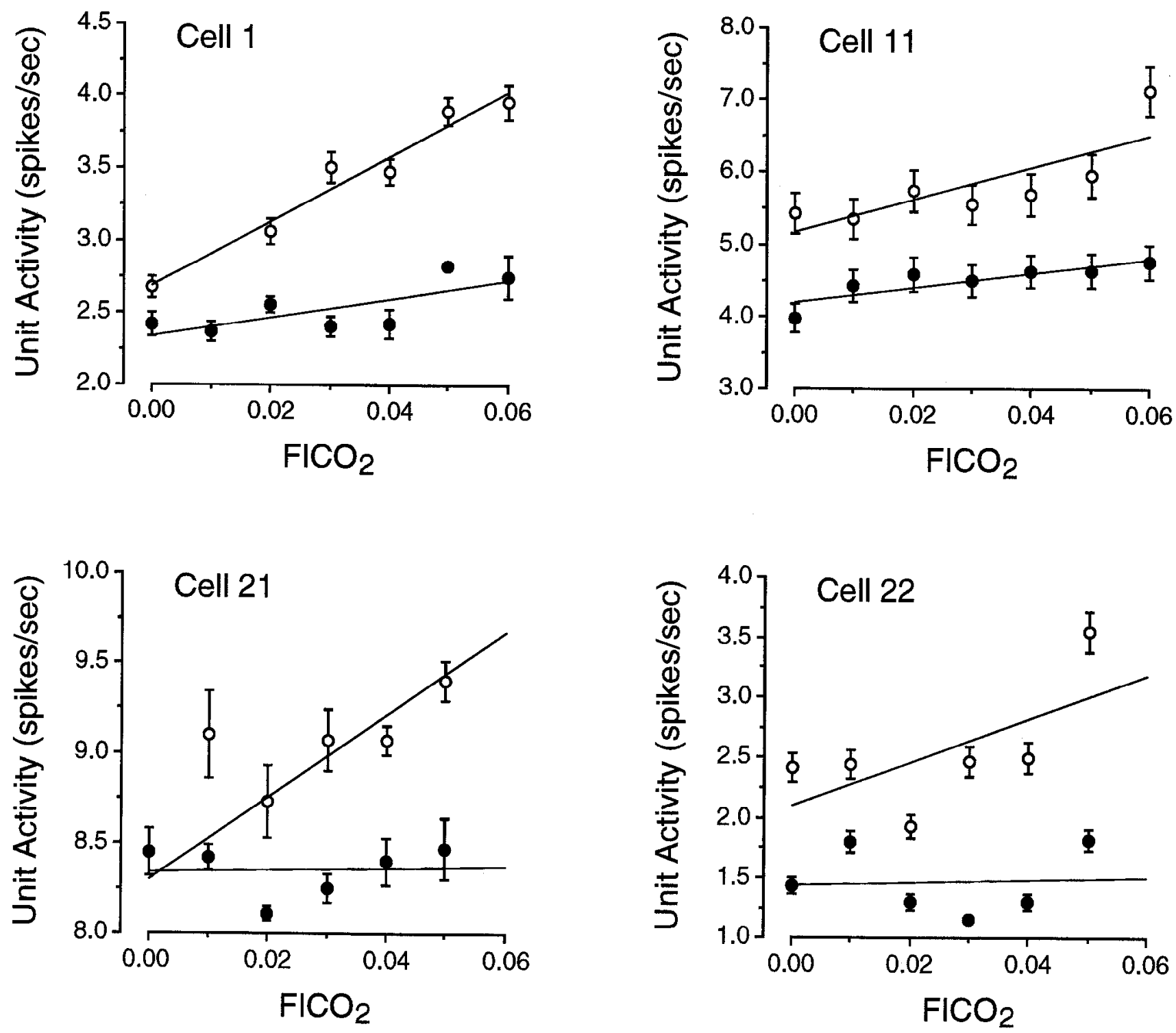

Figure 9. State-dependent responses in neuronal activity for all cells $(n=4)$ responsive to hypercarbic challenge during quiet waking (QW) and then studied during slow-wave sleep (SWS). Open circles, QW data; closed circles, SWS data. Best-fit lines are presented for each trial. The slope of the unit activity response curve to $\mathrm{CO}_{2}$ was significantly lower during SWS than during QW $(p<0.005)$.

of NRO and NRP (Jacobs et al., 1984). These cells were distributed throughout the rostral-caudal extent of NRO $(n=13)$ and all but the most rostral extension of $\operatorname{NRP}(n=17)$; that is no cells were found rostral to AP -9.

We further characterized the distributions of serotonergic neurons responsive to each of the three motor challenges. Cells responsive to locomotor challenge were found throughout the regions described above, and each of the three response patterns described for locomotor challenge were also evenly distributed within the two nuclei. Cells responsive to hypercarbic challenge were also distributed within the two nuclei; these cells were most prevalent, however, at the dorsal-ventral junction of NRO and NRP. Finally, the neurons responsive to feeding, although found throughout both caudal raphe nuclei, were concentrated at AP levels -9 to -10 for cells demonstrating a type I response and within NRP at AP levels -9 and -12 for cells demonstrating a type II response pattern.

\section{Discussion}

Neurons selected for study

The study of neuronal activity in freely moving animals requires extracellular recording, which does not afford direct neurochemical identification of the neurons. Intracellular recording studies of raphe neurons, however, have determined several electrophysiological characteristics of serotonergic raphe neurons, and collectively these characteristics are unique to serotonergic raphe neurons. For neurons within the raphe nuclei, rhythmic firing patterns are specific to serotonergic neurons (Aghajanian and VanderMaelen, 1982). Further, this pattern is lost after treatment with a selective 5-HT neurotoxin (Aghajanian et al., 1978). Additionally, for raphe neurons, only the serotonergic cells have action potential durations $\geq 2 \mathrm{msec}$ with prominent afterhyperpolarizations (Aghajanian and VanderMaelen, 1982). Finally, the only brainstem neurons demonstrating reduced firing rates in SWS and then profound reductions in firing in REMS are mono- 


\section{Locomotor-Responsive Cells}

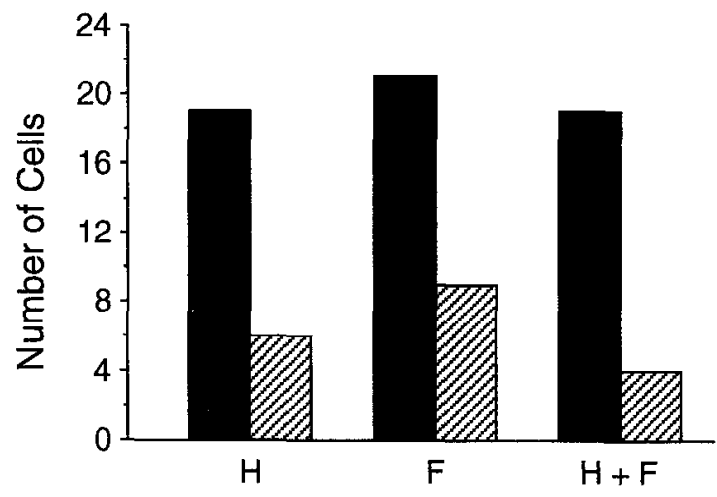

Hypercarbia-Responsive Cells

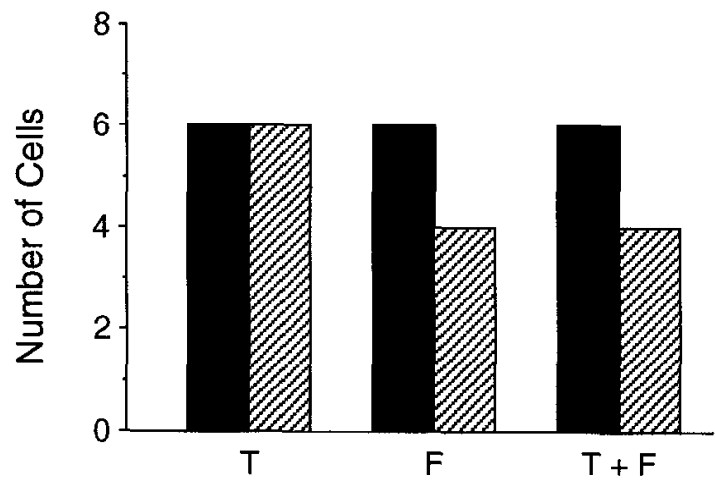

Feeding-Responsive Cells

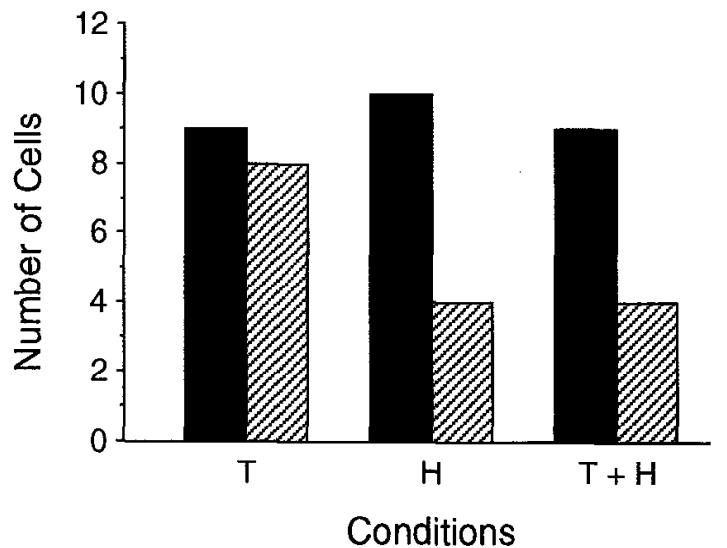

Figure 10. Cross-responsiveness of serotonergic caudal raphe cells to three motor tasks. Data are presented for treadmill-responsive cells (top), hypercarbia-responsive cells (middle), and feeding-responsive cells (bottom). Solid columns, number of cells tested; hatched columns, number of cells responsive to the specific tasks: treadmill-induced locomotion $(T)$; hypercarbic ventilatory challenge $(H)$; and feeding $(F)$.

aminergic neurons (Aston-Jones and Bloom, 1981; Trulson and Jacobs, 1981; Hobson et al., 1983). In the present study, all neurons within NRO or NRP demonstrating sleep state dependence in firing had action potential durations $\geq 2 \mathrm{msec}$ and regular firing rates. We believe, therefore, that all neurons included in our analysis were serotonergic.
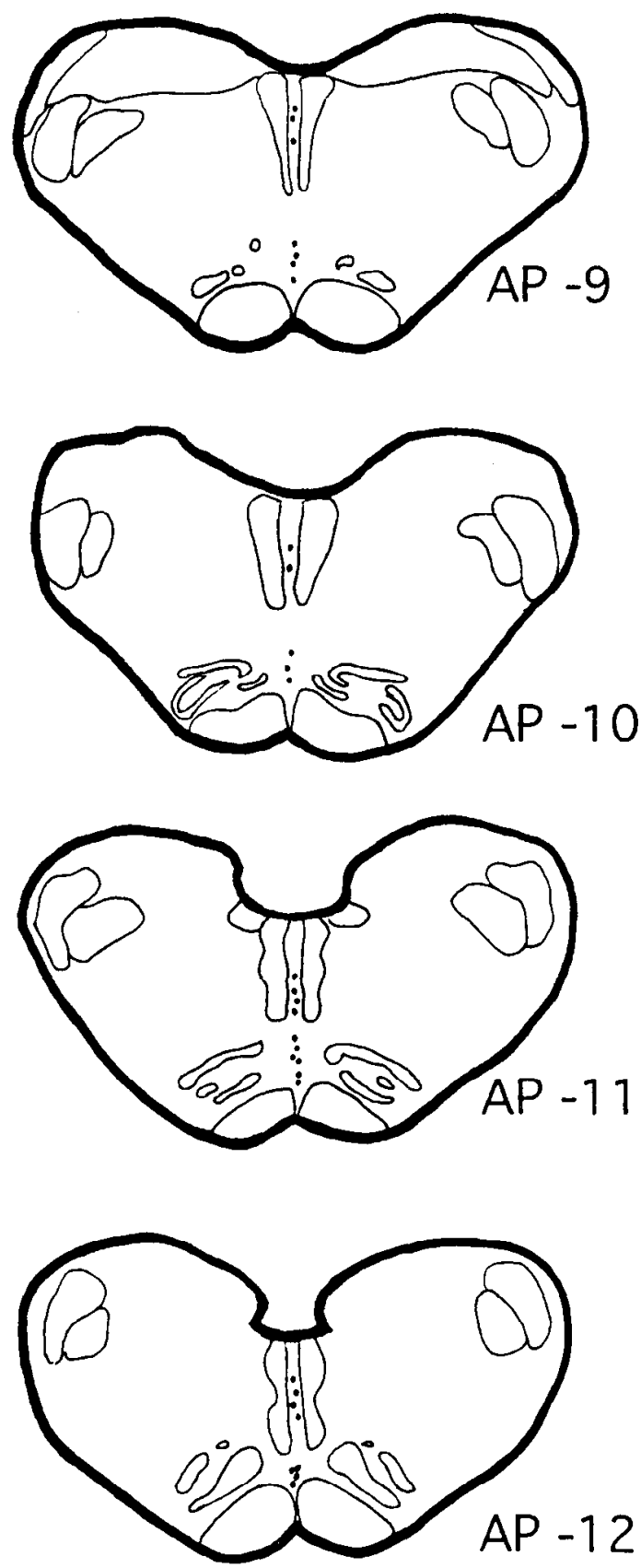

Figure 11. Histological localization of all cells $(n=30)$ meeting criteria of serotonergic neurons.

Another general feature of brainstem serotonergic neurons is autoreceptor-mediated feedback inhibition (Aghajanian et al., 1987). Serotonergic neurons are sensitive to $5-\mathrm{HT}_{1 \mathrm{~A}}$ agonists such as 8-OH DPAT and respond with an inhibition of neuronal activity. This pharmacological response is often used as an additional identifying criterion for serotonergic neurons (McCall and Clement, 1989; Fornal et al., 1994a). In awake cats, the firing rates of pontine raphe serotonergic neurons (DRN and NCS) are suppressed by greater than $90 \%$ of their baseline firing rates after systemic administration of low doses $(\leq 10 \mu \mathrm{g} / \mathrm{kg}$, i.v.) of 8-OH DPAT (Tada et al., 1991; Fornal et al., 1994a). However, in the present study, despite using larger doses of 8-OH DPAT (e.g., $\geq 20 \mu \mathrm{g} / \mathrm{kg}$, i.v.), the mean suppression of 
neuronal activity was less than that observed for pontine raphe serotonergic neurons. The relative lack of responsiveness to 5-HT autoreceptor agonists of medullary serotonergic neurons compared to pontine serotonergic neurons has been described in vitro using a mouse brain preparation (Trulson and Frederickson, 1986) and in vivo using nonselective 5-HT agonists (e.g., LSD and 5-MeODMT) in awake cats (Heym et al., 1982). In the present study, we have demonstrated (1) similar electrophysiological characteristics (long action potentials, regular firing patterns), state dependencies, and motor responses (activation with various challenges and during spontaneous behaviors) for $8-\mathrm{OH}$ DPAT-responsive and -unresponsive cells; and (2) that an inverse relationship exists between firing rate and $8-\mathrm{OH}$ DPAT responsiveness. We therefore believe that 8-OH DPAT responsiveness should not be an absolute criterion for the identification of medullary serotonergic neurons in the freely moving cat. Our data suggest that some caudal raphe serotonergic neurons have a relative lack of impulse-modulating 5-HT autoreceptors, and hence display an insensitivity to $5-\mathrm{HT}_{1 \mathrm{~A}}$ agonist drug administration and higher spontaneous discharge rates as a result of less feedback inhibition. This latter point is consistent with our previous finding that blockade of the autoreceptor with $5-\mathrm{HT}_{1 \mathrm{~A}}$ antagonists activates brain serotonergic discharge under physiological conditions (Fornal et al., 1994a,b).

\section{Neuronal responses to locomotor challenge.}

Motor responses are highly complex and may involve all of the following physiological processes: a heightened level of alertness, facilitation and recruitment of motor units, inhibition or disfacilitation of opposing motor units, proprioceptive feedback, autonomic responses, and alterations in sensory thresholds (for review, see McArdle et al., 1981). Since medullary raphe neurons receive inputs from, or project to, nuclei implicated in all of the above processes (Brodal et al., 1960; Martin et al., 1978; Basbaum and Fields, 1979; Loewy, 1981), the neuronal responses we have described may be related to any or all of the above. Our findings, however, render some possibilities less likely. The increased firing rates during locomotion are probably not attributable to an increase in the subject's level of arousal or alertness during motor challenge. At the end of a locomotor trial, when the treadmill was abruptly turned off, unit activity immediately fell to baseline levels, despite the fact that the animals remained alert and activated. In addition, none of the locomotorresponsive cells showed increased firing rates upon the presentation of inaccessible food through the Plexiglas door of the recording chamber, which typically results in behavioral arousal. Finally, the majority of locomotor responsive cells did not show increases in firing rates during the hypercarbic challenge, when the cats appeared highly alert, demonstrating deep respiratory effort and marked EEG desynchronization.

The results of the present study do not support a selective role for medullary serotonergic neurons in proprioceptive feedback. That is, the activity of a subset of locomotor-responsive neurons (see Fig. 5, middle) was unchanged from a baseline stationary position to low levels of locomotor activity, while increasing at greater speeds without altering the gait. Further, those cells that were activated during spontaneous movements, were not activated during passive movement of the neck or limbs mimicking the spontaneous movements.

To evaluate an autonomic role for these neurons is more difficult. Serotonergic NRO and NRP neurons innervate many CNS regions involved in the regulation of sympathetic and parasym- pathetic nerve activity (Cabot et al., 1979; Loewy, 1981; Howe et al., 1983; Hassleton et al., 1988; Bowker and Abbott, 1990). Although medullary raphe-spinal neurons respond to stimulation of both sympathetic and vagal afferents in paralyzed anesthetized cats, the electrophysiological properties of these neurons are not characteristic of serotonergic neurons (Blair and Evans, 1991). In contrast, identified serotonergic medullary neurons were found unaffected by baroreceptor stimulation and their activity was not temporally related to the cardiac cycle (McCall and Clement, 1989). Our data suggest a stronger relationship between unit activity and motor output than between unit activity and autonomic output. That is, upon termination of a treadmill trial, there is an abrupt reduction in motor output while heart rate and blood pressure fall more gradually, over minutes (Vatner and Murray, 1980). We have shown that unit activity for all treadmill locomotor-responsive neurons fell to, or below, the baseline firing rate within the first $10 \mathrm{sec}$ epoch after locomotion. Thus, activation of serotonergic projections to autonomic centers may occur specifically as part of a motor response. In light of the collateralization of medullary serotonergic neurons to somatic and autonomic neuronal cell groups (Allen and Cechetto, 1994), it is possible that NRO and NRP serotonergic neurons are involved in the integration of motor and autonomic responses to specific motor challenges (for a discussion of this issue, see Jacobs and Fornal, 1993).

Movement-related cells within the medulla have been described (Siegel et al., 1979). There are, however, several important distinctions between the cells described in this article and those previously reported. First, medullary reticular formation neurons $(0.8-2.7 \mathrm{~mm}$ lateral to midline) in freely moving cats are either silent or fire with irregular discharge patterns in QW. A second distinction is that the vast majority of tegmental medullary reticular neurons discharge with similar frequencies in waking and in REMS (Siegel et al., 1979), while the neurons reported in the present study show markedly reduced activity in REMS. Thus, the activity of caudal raphe serotonergic cells is more closely associated with levels of motor activity across all behavioral states. The present study is the first report of sleep state-dependent neurons demonstrating significant relationships between firing rates and levels of locomotor challenge. It is of interest that chemical and electrical stimulation of the medial medullary reticular formation elicits postural atonia, implicating this area in the active inhibition of postural motoneurons in REMS (Lai and Siegel, 1988). Our data in conjunction with this information suggest that within the vicinity of the caudal raphe there are neural mechanisms that are facilitatory and inhibitory to motor output.

For neurons demonstrating increased activity during locomotor challenge, three response patterns emerged, as shown in Figure 5 . These response patterns probably represent a continuum rather than distinct subgroups. It is likely that some, if not all, of the serotonergic neurons recorded in the present study have projections to spinal motoneuronal pools (Martin et al., 1978; Basbaum and Fields, 1979; Bowker et al., 1987). The different locomotor response patterns of serotonergic medullary raphe neurons could represent activation of different motor units within the same muscle or different muscle groups.

\section{Neuronal responses to hypercarbic ventilatory challenge}

The ventilatory response pattern to progressive hypercarbia is a positive linear response in minute ventilation after a threshold $\mathrm{FICO}_{2}$ is reached (Phillipson et al., 1976). As a group, the $\mathrm{CO}_{2}$ - 
responsive serotonergic neurons described here respond linearly beyond a threshold $\mathrm{FICO}_{2}$. Further, the activity of these neurons is related to ventilatory output, specifically to inspiratory amplitude. Holtman et al. (1986a) reported that stimulation of NRO with L-glutamate results in augmentation of the respiratory burst amplitude of phrenic nerve activity. Systemic pretreatment with a 5-HT antagonist prevented the delayed excitatory response to L-glutamate microinjection (Holtunan el al., 1986b), suggesting that serotonergic NRO neurons facilitate phrenic nerve activity. The present results extend these findings by showing that a subset of caudal raphe serotonergic neurons are responsive to a ventilatory challenge and that these neurons are activated in parallel with the hypercapnic ventilatory response.

As is true for the locomotor challenge, response to hypercarbia involves not only motor but autonomic components as well, such as increased sympathetic output to the heart and vasculature (Sechzer et al., 1960). Because a strong relationship exists between neuronal activity and inspiratory amplitude and because medullary serotonergic neurons have not been shown to be affected by manipulations of arterial blood pressure and heart rate (McCall and Clement, 1989), the response of serotonergic medullary neurons to hypercarbic challenge is more likely related to ventilatory output than to autonomic output.

All serotonergic neurons responsive to hypercarbic challenge were also responsive to treadmill challenge. Because the ventilatory response to exercise in cats (Dimarco et al., 1983; Eldridge et al., 1985), as in other species (Dempsey et al., 1985), does not include a hypercarbic component, this suggests that individual serotonergic neurons may be responsive to multiple inputs, such as hypercarbia and locomotion.

Respiratory-related units (RRUs), as defined by methods of Netick and Orem (1981), have been described within the NRO and NRP (Lindsey et al., 1992b; Hosogai et al., 1993). Findings from several studies suggest that these neurons are not serotonergic: the firing rates of NRO and NRP cells with respiratoryrelated activity are not reduced in REMS (Heym et al., 1982), and axonal conduction velocities are greater than what would be expected for serotonergic raphe-spinal neurons (Lindsey et al., 1992a). The serotonergic neurons responsive to hypercarbia in the present study are not RRUs. Our data suggest that $\mathrm{CO}_{2}$ responsive serotonergic cells may provide tonic facilitatory support to respiratory motoneuronal groups, and that the level of tonic support may parallel the ventilatory challenge.

An interesting finding to emerge from our study is the sleep state dependency of the neuronal response to hypercarbia. Recent evidence suggests that central $\mathrm{CO}_{2}$ chemosensitivity is not depressed in sleep (Parisi et al., 1992; Orem and Trotter, 1993), although the motor output response to $\mathrm{CO}_{2}$ is depressed in sleep (Phillipson et al., 1976). A sleep-related reduction in serotonergic input to respiratory musculature might explain at least in part this reduced motor output. There is evidence from other experiments of the potential significance of the reduced serotonergic facilitatory input to motoneurons. In the carbachol nodel of REMS-atonia, the depressed activity of hypoglossal motoneurons was paralleled by a reduction in serotonin levels at the hypoglossal motor nucleus, as measured by microdialysis (Kubin et al., 1994). Further, application of 5-HT to hypoglossal motoneurons restores the depressed motor activity produced by pontine carbachol microinjections (Kubin et al., 1993). Our results suggest that at least one component of the reduced ventilatory responsiveness to hypercarbic challenge during sleep may be a reduction in the facilitatory input of serotonergic NRO and NRP neurons to respiratory motoneurons or premotor cells.

\section{Neuronal responses to feeding}

NRO and NRP neurons have been implicated in control of gastrointestinal secretion, motility, and tone (McCann et al., 1989; White et al., 1991). Additionally, a subset of pontine serotonergic neurons show substantially increased firing rates (two- to fourfold) during feeding behaviors (Ribiero-do-Valle et al., 1989; Jacobs and Fornal, 1991). The present results indicate that there may be two distinct neuronal responses to feeding for medullary raphe cells. The type I feeding response we describe is temporally related to ingestive behaviors (mastication and swallowing). These cells could represent premotoneurons to cranial nerves involved in these behaviors. In contrast, the type II (delayed and prolonged) response pattern would more temporally represent gastric motility and/or secretion, and could represent vagal inputs.

\section{Responsiveness to more than one motor task}

Caudal raphe serotonergic neurons are responsive to specific motor challenges and these responses are largely tonic increases in activity. Importantly, the majority of neurons tested with all three challenges were responsive to more than one challenge. Collectively, our findings support the hypothesis that serotonergic caudal raphe cells may serve primarily as tonic gain setters for multiple motor tasks.

\section{References}

Aghajanian GK, VanderMaelen CP (1982) Intracellular recordings from serolunergic dorsal raphe neurons: pacemaker potentials and the effect of LSD. Brain Res 238:463-469.

Aghajanian GK, Wang RY, Barbaran JM (1978) Serotonergic and nonserotonergic neurons of the dorsal raphe: reciprocal changes in firing induced by peripheral nerve stimulation. Brain Res 153:169-175.

Aghajanian GK, Sprouse JS, Rasmussen K (1987) Physiology of the midbrain serotonergic system. In: Psychopharmacology: the third generation of progress (Meltzer HY, ed), pp 141-149. New York: Raven.

Allen GV, Cechetto DS (1994) Serotoninergic and non-serotoninergic neurons in the medullary raphe system have axon collateral projections to autonomic and somatic cell groups in the medulla and spinal cord. J Comp Neurol 350:357-366.

Aston-Jones G, Bloom FE (1981) Activity of norepinephrine-containing locus coeruleus neurons in behaving rats anticipales fluctuations in the sleep-waking cycle. J Neurosci 1:876-886.

Basbaum AI, Fields HL (1979) The origin of descending pathways in the dorsolateral funiculus of the spinal cord of the cat and rat: further studies on pain modulation. J Comp Neurol 187:513-532.

Blair RW, Evans AR (1991) Responses of medullary raphe-spinal neurons to electrical stimulation of the thoracic sympathetic afferents, vagal afferents, and to other sensory inputs in cats. $\mathbf{J}$ Neurophysiol $66: 2084-2094$

Bowker RM, Abbott LC (1990) Quantitative re-evaluation of descending serotonergic and non-serotonergic projections from the medulla of the rodent: evidence for extensive co-existence of serotonin and peptides in the same spinally projecting neurons, but not from the nucleus raphe magnus. Brain Res 512:15-25.

Bowker RM, Reddy VK, Fung SJ, Chan JYH, Barnes CD (1987) Serotonergic and non-serotonergic raphe neurons projecting to the feline lumbar and cervical spinal cord: a quantitative horseradish peroxidase-immunocytochemical study. Neurosci Lett 75:31-37.

Brodal A, Taber E, Walberg F (1960) The raphe nuclei of the brain stem in the cat. II. Efferent connections. J Comp Neurol 114:239260 .

Cabot JB, Wild JM, Cohen DH (1979) Raphe inhibition of sympathetic preganglionic neurons. Science 203:184-186.

Chadha TS, Watson H, Birch S, Jenouri JA, Schneider AW, Cohn MA Sackner MA (1982) Validation of respiratory inductive plethysmog- 
raphy using different calibration positions. Am Rev Respir Dis 125: 644-649.

Dempsey JA, Vidruck EH, Mitchell GS (1985) Exercise hyperpnea and locomotion: parallel activation from the hypothalamus. Science 211: 844-846.

Dimarco AF, Romaniuk JR, von Euler C, Yamamoto Y (1983) Immediate changes in ventilation and respiratory pattern with onset and offset of locomotion in the cat. J Physiol (Lond) 343:1-16.

Eldridge FL, Millhorn DE, Kiley JP, Waldrop TG (1985) Stimulation by central command of locomotion, respiration and circulation during exercise. Respir Physiol 59:313-337.

Fornal CA, Litto WJ, Metzler CW, Marrosu F, Tada K, Jacobs BL (1994a) Single-unit responses of serotonergic dorsal raphe neurons to $5-\mathrm{HT}_{1 \mathrm{~A}}$ agonist and antagonist drug administration in behaving cats. J Pharmacol Exp Ther 207:1345 1358.

Fornal CA, Metzler CW, Veasey SC, Dourish CT, Jacobs BL (1994b) WAY-100635, a potent and selective $5-\mathrm{HT}_{1 \mathrm{~A}}$ receptor antagonist, increases serotonergic neuronal activity and blocks the action of $8-\mathrm{OH}$ DPAT in behaving cats. Soc Neurosci Abstr 20:1544.

Frank K, Fuortes HGF (1955) Potentials recorded from the spinal cord with microelectrodes. J Physiol (Lond) 130:626-654.

Fraser RG, Paré JAP, Paré PD, Fraser RS, Genereux GD (1988) The normal chest. In: Diagnoses of disease of the chest, pp 260-261. Philadelphia: Saunders.

Fung SL, Barnes CD (1989) Raphe-produced excitation of spinal cord motoneurons in the cat. Neurosci Lett 103:185-190.

Gregor RJ, Roy RR, Whiting WC, Lovely RG, Hodgson JA, Edgerton VA (1988) Mechanical output of the cat soleus during treadmil locomotion: in vivo vs. in silu characteristics. J Biomech 21:721-732.

Hassleton JR, Winters RW, Liskowsky DR, Hasselton CL, McCabe PM Schneiderman N (1988) Anatomical and functional connections of neurons of the rostral medullary raphe of the rabbit. Brain Res 453 : $176-182$.

Heym J, Jacobs BL (1986) Recording single unit activity of neurons in freely moving cats. In: Modern methods in pharmacology: electrophysiological techniques (Gellar HM, ed), pp 17-34. New York: Liss.

Heym J, Steinfels GF, Jacobs BL (1982) Activity of serotonin-containing neurons in the nucleus raphe pallidus of freely moving cats. Brain Res 251:259-276.

Hobson JA, McCarley RW, Nelson JP (1983) Location and spike-train characteristics of cells in anterodorsal pons having selective decreases in firing rate during desynchronized sleep. J Neurophysiol 50:770783.

Holtman JR Jr, Anastasi NC, Norman WP, Dretchen KL (1986a) Effect of electrical and chemical stimulation of the raphe obscurus on phrenic nerve activity in the cat. Brain Res 362:214-220.

Holtman JR Jr, Dick TE, Berger AJ (1986b) Involvement of serotonin in the excitation of phrenic motoneurons evoked by stimulation of the raphe obscurus. J Neurosci 6:1185-1193.

Hosogai M, Matsuo S, Nakao S (1993) Firing pattern and location of respiratory neurons in cat medullary raphe nuclei. Neurosci Lett 161 : $149-152$.

Howe PRC, Kuhn DM, Minson JB, Stead BH, Chalmers JP (1983) Evidence for a bulbospinal serotonergic pressor pathway in the rat brain. Brain Res 270:29-36.

Jacobs BL, Azmitia EC (1992) Structure and function of the brain serotonin system. Physiol Rev 72:165-229.

Jacobs BL, Fornal CA (1991) Activity of brain serotonergic neurons in the behaving animal. Pharmacol Rev 43:563-578.

Jacobs BL, Fornal CA (1993) 5-HT and motor control: a hypothesis. Trends Neurosci. 16:346-352.

Jacobs BL, Gannon PJ, Azmitia EC (1984) Atlas of serotonergic cell bodies in the cat brainstem: an immunocytochemical analysis. Brain Res Bull 13:1-13.

Kubin L, Tojima H, Davies RO, Pack AI (1992) Serotonergic excitatory drive to hypoglossal motoneurons in the decerebrate cat. Neurosci Lett 139:243-248.

Kubin L, Reignier C, Woch G, Tojima H, Pack AI, Davies RO (1993) Serotonin (5-HT) microinjected into the hypoglossal (XII) nucleus reduces the depression of XII nerve activity during REM sleep-like atonia. Soc Neurosci Abstr 19:987.

Kubin L, Reignier C., Tojima H, Taguchi O, Pack AI, Davies RO (1994) Changes in serotonin level in the hypoglossal nucleus region during carbachol-induced atonia. Brain Res 645:291-302.
Kuypers HGJM (1981) Anatomy of the descending pathways. In: Handbook of physiology, The nervous system, Vol II, Motor control, Pt I (Brookhart JM, Mountcastle VB, Brooks VB, Geiger SR, eds), pp 597-666. Bethesda, MD: American Physiological Society.

Lai YY, Siegel JM (1988) Medullary regions mediating atonia. J Neurosci 8:4790-4796.

Lindsey BG, Hernandez YM, Morris KF, Shannon R (1992a) Functional connectivity between brainstem midline neurons with respiratory modulated firing rates. J Neurophysiol 67:890-902.

Lindsey BG, Hernandez YM, Morris KF, Shannon R, Gerstein GL (1992b) Respiratory related neural assemblies in the brainstem midline. J Neurophysiol 67:905-922.

Loewy AD (1981) Raphe pallidus and raphe obscurus projections to the intermediolateral cell column in the rat. Brain Res 222:129-133.

Martin RF, Jordan LM, Willis WD (1978) Differential projections of cat medullary raphe neurons demonstrated by retrograde labeling following spinal cord lesions. J Comp Neurol 182:77-88.

McArdle WD, Katch FI, Katch VL (1981) Cardiovascular regulation and integration. Skeletal muscle: structure and function. In: Exercise physiology: energy, nutrition and human performance, pp 177-247. Philadelphia: Lea and Febiger.

McCall RB, Aghajanian GK (1979) Serotonergic facilitation of facial motoneuron excitation. Brain Res 169:11-27.

McCall RB, Clement ME (1989) Identification of serotonergic and sympathetic neurons in the medullary raphe nuclei. Brain Res 477: $172-182$.

McCann MJ, Herman GE, Rogers RC (1989) Nucleus raphe obscurus (nRO) influences vagal control of gastric motility in rats. Brain Res 486:181-184.

McGinty DJ, Harper RM (1976) Dorsal raphe neurons: depression of firing rates during sleep in cats. Brain Res 101:569-575.

Millhorn DE (1986) Stimulation of raphe (obscurus) nucleus causes long-term potentiation of phrenic nerve activity in cat. J Physiol (Lond) 381:169-179.

Netick A, Orem J (1981) Erroneous classification of neuronal activity by the respiratory modulation index. Neurosci Lett 21:301-306.

Orem J, Trotter RH (1993) Increased angmenting and late inspiratory medullary neuronal activity during REM sleep in the adult cat. Soc Neurosci Abstr 19:1192.

Parisi RA, Edclman NH, Santiago TV (1992) Central respiratory carbon dioxide chemosensitivity does not decrease during sleep. Am Rev Respir Dis 145:832-836.

Phillipson EA, Kozar LF, Murphy E (1976) Respiratory compensation in awake and sleeping dogs. J Appl Physiol 40:895-902.

Ribeiro-do-Valle LE, Fornal CA, Litto WJ, Jacobs BL (1989) Serotonergic dorsal raphe unit activity related to feeding/grooming behaviors in cats. Soc Neurosci Abstr 15:1283.

Ribeiro-do-Valle LE, Metzler CE, Jacobs BL (1991) Facilitation of masseter EMG and masseteric (jaw closure) reflex by serotonin in behaving cats. Brain Res 550:197-204.

Roberts MH, Davies M, Girdlestone D, Foster GA (1988) Effects of 5-hydroxytryptamine agonists and antagonists on the responses of rat spinal motoneurons to raphe obscurus stimulation. $\mathrm{Br} \mathrm{J}$ Pharmacol 95:437-448.

Santiago TV, Sinha AK, Edelman NH (1981) Respiratory flow-resistive load compensation during sleep. Am Rev Respir Dis 123:382-387.

Sechzer PH, Egbert LD, Linde HW, Cooper DY, Dripps RD, Price HL (1960) Effect of $\mathrm{CO}_{2}$ inhalation on arterial pressure, EKG and plasma catecholamines and $17-\mathrm{OH}$ corticosteroids in normal man. J Appl Physiol 15:454-458.

Siegel JM, Wheeler RL, McGinty DJ (1979) Activity of medullary reticular formation neurons in the unrestrained cat during waking and sleep. Brain Res 179:49-60.

Taber EA, Brodal A, Walberg F (1960) The raphe nuclei of the brainstem in the cat. I. Normal topography and cytoarchitecture and general discussion. J Comp Neurol 114:161-188.

Tada K, Fornal CA, Marrosu F, Metzler CW, Jacobs BL (1991) Singleunit responses of $\mathbf{n}$. raphe dorsalis and centralis superior neurons to $5-\mathrm{HT}_{1 \mathrm{~A}}$ drugs in behaving cats. Soc Neurosci Abstr 17:1437.

Trulson ME, Frederickson CJ (1986) A comparison of the electrophysiological and pharmacological properties of serotonin-containing neurons in the nucleus raphe dorsalis, raphe medianus and raphe pallidus recorded from mouse brain slices in vitro: role of autoreceptors. Brain Res Bull 18:179-190.

Trulson ME, Jacobs BL (1981) Raphe unit activity in freely moving 
cats: correlation with level of behavioral arousal. Brain Res 163:105_ 115.

van Lunteren $\mathrm{E}$ (1987) The interactive effects of $\mathrm{CO}_{2}$ and upper airway negative pressure. J Appl Physiol 63:229-237.

Vatner SF, Murray PA (1980) Cardio-circulatory adlaptations to severe exercise in conscious dogs. In: Exercise bioenergetics and gas exchange (Cerretelli P, Whipp BJ, eds), pp 253-263. Amsterdam: Elsevier/North Holland.
White RL, Rossiter CD, Hornby PJ, Harmon JW, Kasbekar DK, Gillis RA (1991) Excitation of neurons in the medullary raphe increases gastric acid and pepsin production in cats. Am J Physiol 260:G91G96.

Willis WS (1984) 'The raphe spinal system. In: Brainstem control of spinal cord function (Barnes CD, ed), pp 141-214. New York: Academic. 